\title{
What is the Probability of RECEIVING A U.S. PATENT?
}

\author{
Michael Carley, Deepak Hegde, and Alan Marco ${ }^{\dagger}$
}

17 YALE J.L. \& TECH. 203 (2015)

\begin{abstract}
What proportion of patent applications filed at the U.S. Patent and Trademark Office (USPTO) are eventually granted? Many experts have suggested that the USPTO approves nearly all applications, blaming this apparent leniency for many problems with the U.S. patent system. To test this assumption, we follow the prosecution histories of 2.15 million U.S. patent applications from 1996 to mid-2013. We find that only $55.8 \%$ of the applications emerged as patents without using continuation procedures to create related applications. The allowance rate has decreased substantially over time, particularly for applications in the "Drugs and Medical Instruments" and "Computers and Communications" fields. Furthermore, applications filed by small firms were less likely to emerge as patents than those filed by large firms. We discuss the implications of our findings for inventors, policymakers, and legal scholars.
\end{abstract}

\section{TABLE OF CONTENTS}

Introduction. 204

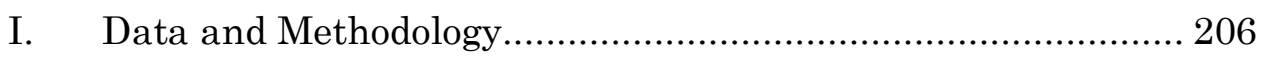

II. Patent Examination in the United States ............................. 207

A. The Examination Process............................................... 207

B. Continuation Procedures.............................................. 209

III. Allowance Rates Across Technology Fields .......................... 212

IV. Allowance Rates Across Inventor Types ............................... 213

V. Conclusion................................................................ 215

Appendix.................................................................... 217

+ The authors thank Wesley Cohen, Paul D'Agostino, Charles Eloshway, Kira Fabrizio, Dan Hunter, Jenny Kuan, Joanne Oxley, Gregory Mills, Cecil Quillen, Binta Robinson, Patrick Ross, Robert Seamans, and Arvids Ziedonis for helpful discussions and suggestions. Alan Marco is the Chief Economist at the U.S. Patent and Trademark Office (USPTO), Michael Carley is a Senior Data Analyst at TMobile, and Deepak Hegde is an Assistant Professor at New York University and Thomas Alva Edison Research Fellow at the USPTO. Hegde's research was funded by the 2012-2013 Kauffman Faculty Fellowship. The analysis and recommendations in this manuscript, however, are solely the authors' and do not necessarily reflect the views of either the USPTO or the Kauffman Foundation. 


\section{INTRODUCTION}

Inventors choose to protect their inventions with patents for a variety of reasons. ${ }^{1}$ A key element of inventors' cost-benefit calculus regarding patents is the expectation that their applications will succeed. Unfortunately, there is little information about the historical rates at which the United States Patent and Trademark Office (USPTO) grants patents. This lack of information about the probability of obtaining a patent makes it difficult for inventors to determine the best way to protect their intellectual property.

The absence of systematic evidence on patent allowance rates also skews policy discussions about the patent examination standards employed by the USPTO. Some scholars argue that the USPTO grants patents too easily, pointing to patents like the "Beerbrella" (U.S. Patent \#6637447), swinging methods (U.S. Patent \#6368227), and a user-operated amusement apparatus for kicking the user's buttocks (U.S. Patent \#6293974). These scholars argue that a large number of such frivolous, "rubber-stamped" patents are hindering, rather than promoting, the U.S. innovation system. ${ }^{2}$ For example, some entities, often referred to as "patent trolls," allegedly obtain patents with dubious claims solely to extract rents from genuine inventors who may appear to be infringing on the entities' patents. Judge Posner recently opined that "the problem of patent trolls is a function in part of the promiscuity with which the patent office has issued patents."3

Despite numerous allegations of USPTO laxity and calls for reforms based on anecdotal observations of silly patents, few studies have attempted to calculate the actual percentage of U.S. patent applications that succeed. The calculation of patent allowance rates, while seemingly simple, is complicated by several aspects of the patent examination process. First, patent applications that are initially rejected after examination can produce "new," closely related applications called "continuations." Continuations are difficult to track, but may ultimately emerge as patents. Second, the USPTO publishes examination outcomes only for granted applications, if filed before November 29, 2000, or for applications pending eighteen

1 See, e.g., Wesley Cohen et al., Protecting Their Intellectual Assets: Appropriability Conditions and Why US Manufacturing Firms Patent (or Not), (Nat'l Bureau of Econ. Research, Working Paper W7552, 2000).

2 See, e.g., James Bessen \& Michael J. Meurer, Patent Failure: How Judges, Bureaucrats, and Lawyers Put Innovators at Risk 3 (2008); AdAm B. Jaffe \& Josh Lerner, Innovation and Its Discontents: How Our Broken Patent System is Endangering Innovation and Progress, and What to Do About It 25-26 (2004); Stephen A. Merrill et Al., Committee on Intellectual Property Rights in the Knowledge-Based Economy, A Patent System for the 21st Century 5255 (2004).

3 Richard Posner, Patent Trolls-Posner, The Becker-Posner Blog (July 21, 2013, 5:12PM), http://www.becker-posner-blog.com/2013/07/patent-trollsposner.html. 
months after application date if filed on or after November 29, 2000. ${ }^{4}$ Third, applicants alter the claims in their applications during the examination process. The allowance of some patentable claims within an application is not the same as the allowance of an application as it was filed, and this distinction should be taken into account in any discussion of allowance rates, particularly as it pertains to the extent of scrutiny associated with the examination process.

In this study, we address the above challenges by analyzing unique application-level data available internally at the USPTO. The data tracks 2.15 million utility patent applications filed from 1996 to 2005 and examined until June 30, 2013, by which time $99.8 \%$ of the progenitor applications had been granted or abandoned. 5 "Progenitor applications" are applications unrelated to any previously filed U.S. patent applications. This allows us to link each progenitor application to related subsequent applications produced by various continuation procedures. We can thereby accurately estimate the probability of allowance without the limitations of previous studies based on partial samples of published applications or exit cohorts. ${ }^{6}$

In order to capture the complexity of the examination process, we calculate three measures of patent allowance rates: (i) first-action allowance rate, the proportion of progenitor applications allowed without further examination; (ii) progenitor allowance rate (or simply, allowance rate), the proportion of progenitor applications allowed without any continuation procedure, and (iii) family allowance rate, the proportion of progenitor applications that produce at least one patent, including the outcomes of continuation applications that emerge from progenitor applications.

4 See 35 U.S.C. $\S 122(b)(2)(B)$ (2012) (describing when applicants can request that applications not be published); Domestic Publication of Foreign Filed Patent Applications of 1999, Pub. L. No. 106-113 § 4502, 113 Stat. 1501 (1999).

5 Since the average patent application pends for four to five years at the USPTO before it is granted, a non-trivial fraction of applications filed after 2005 are still pending, making it impossible to calculate definitive allowance rates for applications filed in the latter years of our sample.

6 Data on unpublished applications is not made available in order to protect applicants who may abandon their applications prior to the 18-month publication date. If unpublished applications are more likely to be abandoned, then allowance rates based on publicly available data (i.e., published applications) would be biased upwards. See Mark A. Lemley \& Bhaven Sampat, Is the Patent Office a Rubber Stamp?, 58 EMORY L.J. 101, 106-07 (2009) (analyzing a small sample of 9,960 published applications); Cecil D. Quillen, Jr. \& Ogden H. Webster, Continuing Patent Applications and Performance of the U.S. Patent and Trademark OfficeExtended, 12 FED. CIR. B.J. 35, 36-37 (2002) [hereinafter Quillen \& Webster, Continuing Patent Applications] (noting that data for applications filed before 1980 is not available); Cecil D. Quillen, Jr. \& Ogden H. Webster, Continuing Patent Applications and Performance of the U.S. Patent Office-One More Time, 18 FED. CIR. B.J. 379 (2009) [hereinafter Quillen \& Webster, One More Time] (explaining the difficulties associated with linking original applications to their corresponding continuations). 


\section{DATA AND METHODOLOGY}

The data for our analysis are drawn from the USPTO's internal databases, which provide the essential records for the public Patent Application and Information Retrieval (PAIR) system. These internal databases include information on the prosecution histories of every published patent application filed at the USPTO, including application filing dates, pending application status, and continuation applications. The USPTO publishes examination outcomes through its PAIR system for applications pending 18 months after application date, if filed on or after November 29, 2000, with exceptions made for applications that are filed with a non-publication request. ${ }^{7}$ The chief advantage of this internal data is that it permits us to observe the patent prosecution histories of applications filed at the USPTO before November 29, 2000 , as well as those of unpublished applications filed after this date. We refined our sample population of all patent applications filed at the USPTO after January 01, 1996 to retain only utility patent applications.

We then tracked the allowances, abandonments, and continuations for all progenitor applications that entered patent examination for the first time during 1996-2005. For most applications, we did not observe the final examination outcome until four to five years after the filing date. Our choice of 2005 as the last cohort year limits the number of applications still pending as of June 30, 2013 in our study to 18,270 (less than $1 \%$ of the 2.15 million applications), thereby minimizing censoring errors.

We identified certain application characteristics based on the information contained in USPTO internal guidelines as well as other publicly available sources. First, we determined the application origin (U.S. or foreign) based on the address of the first named inventor on each application. We then determined if the application was filed by a "large" or "small" entity based on USPTO information about the fees paid by the applicants at the time of filing. ${ }^{8}$ Finally, we used the National Bureau of Economics Research (NBER) classification scheme to aggregate the more than five hundred USPTO technology classes into six broad technology fields (Chemical; Drugs and Medical; Electrical and Electronics; Computers and Communications; Mechanical; and a miscellaneous "Other") for ease of discussion. ${ }^{9}$

7 See 35 U.S.C. $§ 122$ (2012). For an analysis of the percentage of inventors who file non-publication requests, see Stuart Graham \& Deepak Hegde, Disclosing Patents' Secrets, SCIENCE, Jan. 16, 2015, at 236-237.

8 Small entities, defined as those with five hundred or fewer employees, qualify for a discount on patent application fees.

9 See Bronwyn H. Hall, Adam B. Jaffe \& Manuel Trajtenberg, The NBER Patent Citations Data File: Lessons, Insights (Nat'l Bureau of Econ. Research, Working Paper W8498, 2001), available at http://www.nber.org/papers/w8498.pdf. 


\section{PATENT EXamination In The United STATES}

\section{A. The Examination Process}

We simplify our description of the patent examination process to discuss only events relevant to our objective. ${ }^{10}$ Accordingly, Figure 1 presents a stylized version of the patent examination process using data from the 1996-2005 filing cohorts of progenitor applications. Each application is queued for examination and then docketed to an examiner. Incomplete or unpaid applications are considered abandoned and are not docketed to an examiner. The first substantive examination of the application is called the "first action on the merits" (or simply "first action"). The first action includes a search report listing relevant prior art that supports the examiner's decision of either allowance or non-final rejection. The USPTO allowed $11.4 \%$ of the progenitor applications at first action and delivered a non-final rejection decision for $86.4 \%$ of the applications, with the remaining $2.3 \%$ abandoned prior to a first action decision. The Office allowed $36.1 \%$ of the progenitor applications after one or more rounds of amendments and negotiations with the examiner, while $14.5 \%$ were abandoned between non-final and final rejection. The remaining $38.7 \%$ of progenitor applications received a final rejection.

[Figure 1 on next page]

10 The USPTO's official utility patent application filing guide provides a more comprehensive description of the rules and procedures. See Nonprovisional (Utility) Patent Application Filing Guide, U.S. Patent \& Trademark Office, http://www.uspto.gov/patents/resources/types/utility.jsp (last updated Jan., 2014). 


\section{Figure 1: The U.S. Patent Examination Process}

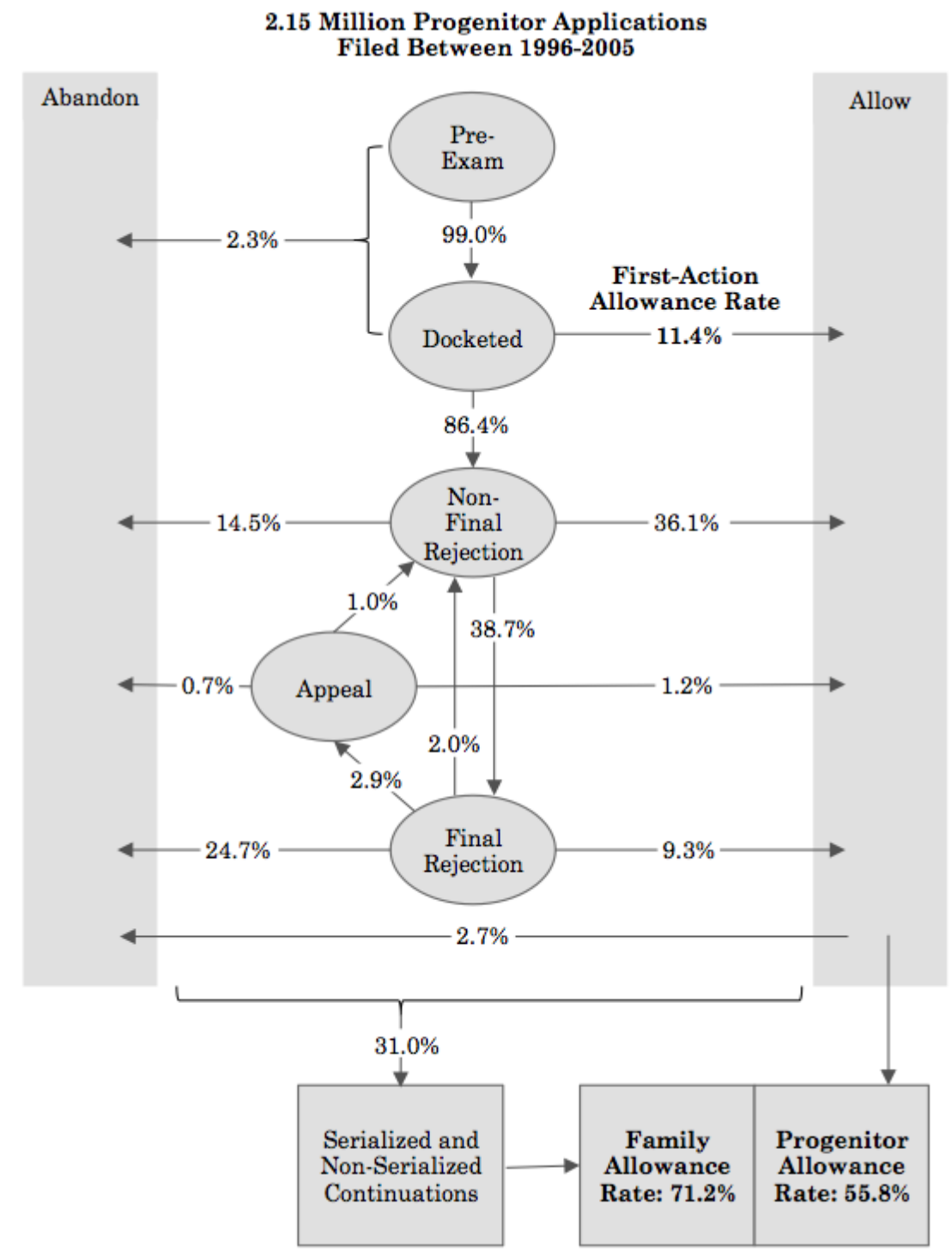

Figure 1 shows a simplified representation of the U.S. patent examination process. It also shows the key intermediate and final outcomes, as of June 30, 2013, for the 2.15 million applications filed for the first time ("progenitor" applications) between 1996 and 2005. The percentage indicated at each transition state reflects the percentage of the total progenitor applications that reached the state. First-action allowance rate refers to the proportion of progenitor applications that were allowed without amendment; Progenitor allowance rate refers to the proportion of progenitor applications that were eventually allowed and patented without continuation processes; Family allowance rate refers to the proportion of progenitor applications that produced at least one patent, including the allowances of continuation applications that emerged from the progenitors. Abandonments and allowances may not sum to $100 \%$ due to rounding. 
For most applications, therefore, patent prosecution ends with patent issue or with abandonment. Applications are considered abandoned if the applicant does not respond to the examiner's decision by the stipulated deadlines or if the applicant expressly requests abandonment. Applicants can, however, continue to submit amended applications even after receiving a final rejection. Of applications that received a final rejection, 9.3\% were subsequently allowed after further amendments. Applicants can also formally appeal a final rejection to the Board of Patent Appeals and Interferences. Accordingly, $7.5 \%$ of final rejections were subject to appeals, $41.4 \%$ of which resulted in allowances. Overall, 55.8\% of progenitor applications filed between 1996 and 2005 and examined before mid2013 emerged as patents without the use of continuation procedures.

\section{B. Continuation Procedures}

Applicants can continue prosecution after receiving a final rejection through various continuation procedures. Some scholars have blamed continuation procedures for abuses of the patent system such as submarine patents (patents that are intentionally delayed from publication and issue by the applicant for a long time), long pending patent applications, and low-quality patents; 11 others have pointed out that continuation procedures enable applicants to update pending applications. ${ }^{12}$

Thirty-one percent of progenitor applications utilized at least one continuation procedure. Continuation procedures fall into two broad categories: non-serialized and serialized. 13 Non-serialized continuations do not receive a new serial number and are immediately docketed to the same examiner that prosecuted the progenitor; the progenitor application is then considered abandoned. Requests for Continued Examination (RCEs) are by far the most common type of non-serialized continuations, and applicants may file an RCE multiple times during prosecution. ${ }^{14}$ At least one RCE was filed by $19.5 \%$ of all applicants, and $38.7 \%$ of applicants that received a non-final rejection

11 See Mark A. Lemley \& Kimberley A. Moore, Ending Abuse of Patent Continuations, 84 B.U. L. REV. 63, 74-76 (2004).

12 See Deepak Hegde et al., Pioneering Inventors or Thicket-Builders: Which Firms Use Continuations in Patenting?, 55 MGMT. ScIEnce 1214, 1224-25 (2009).

13 Serialized continuations can be exercised at any point during patent examination. Non-serialized continuations may only be used after particular events in prosecution, typically after final rejection.

14 There have been several incarnations of non-serialized continuations, including Continued Prosecution Applications (CPAs), Rule 129 continuations (R129s), and File Wrapper Continuations (FWCs). The most recent incarnation (and by far the most prevalent) is the Request for Continued Examination (RCE). Throughout this section, we refer collectively to all of these non-serialized continuations as RCEs. Until November 2009, RCEs were put on the "amended docket," which meant that the examiner had to respond within two months. Since that time, RCEs have gone on the "special new docket," meaning that the examiner has more discretion as to when to respond (similar to newly docketed applications). 
filed an RCE. If one includes allowances of non-serialized continuation applications, the allowance rate jumps from $55.8 \%$ to $69.2 \%$.

In contrast to non-serialized continuations, serialized continuations are treated as new applications. They receive new serial numbers and are docketed to examiners based on the classification of the new application. There are three types of serialized continuations: continuation (CON), continuation-in-part (CIP), and divisional (DIV). A simple continuation of a parent application enables applicants to receive the benefit of the parent's priority date, so long as the CON is limited to the specification described in the parent application. Continuations-in-part allow applicants to introduce new subject matter to an existing application. Divisional applications allow applicants to separate claimed inventions when two or more distinct inventions are claimed in the same application. Serialized continuations, with the exception of new matter added in CIPs, receive the priority date of the progenitor application if the progenitor is pending when the serialized continuation is filed. The progenitor does not have to be abandoned, so both applications may proceed through the examination process in parallel. As a result, one progenitor application can produce a chain of serialized continuations resulting in multiple patents, which complicates the calculation of progenitor allowance rates. As of June 30, 2013, 15.8\% of progenitor applications resulted in at least one serialized continuation. Overall, $71.2 \%$ of progenitor applications resulted in at least one patent after counting allowance of continuation applications.

Figure 2 plots the three allowance rates by progenitor cohort year. The figure shows that the probability of allowance is substantially lower for the more recent cohorts of applications. The striking decline in both first-action allowance rates and progenitor allowance rates is unlikely to be due to censoring, since the mean pendency between application date and first-action date was 21.1 months and mean pendency between application date and disposal date was 29.1 months. Although less than $1 \%$ of the progenitor applications in our study were pending as of June 30, 2013, a larger proportion of abandoned progenitors have pending continuation applications, which potentially biases our family allowance rates downward for later years. We account for this by calculating the maximum possible family allowance rate that would occur if all pending applications were to eventually issue. Dashed lines in Figure 2 represent maximum allowance rates. This correction demonstrates that the average family allowance rate for our cohorts could be at most $72.3 \%$ (as compared to the rate of $71.2 \%$ based on disposals observed to date), so the decline in allowance rates between 1996-2005 remains quite robust. ${ }^{15}$

15 The effect of censoring is more pronounced for more recent cohorts and increased sharply after 2005, thus validating 2005 as the cut-off year for our study. Figure A1 of the Supplementary Appendix presents the lower and upper bounds for each of the three allowance rates for 1991 to 2010. As the window between filing and 


\section{Figure 2: Trends in Allowance Rates for Applications Filed from 1996-2005 and Examined Before Mid-2013}

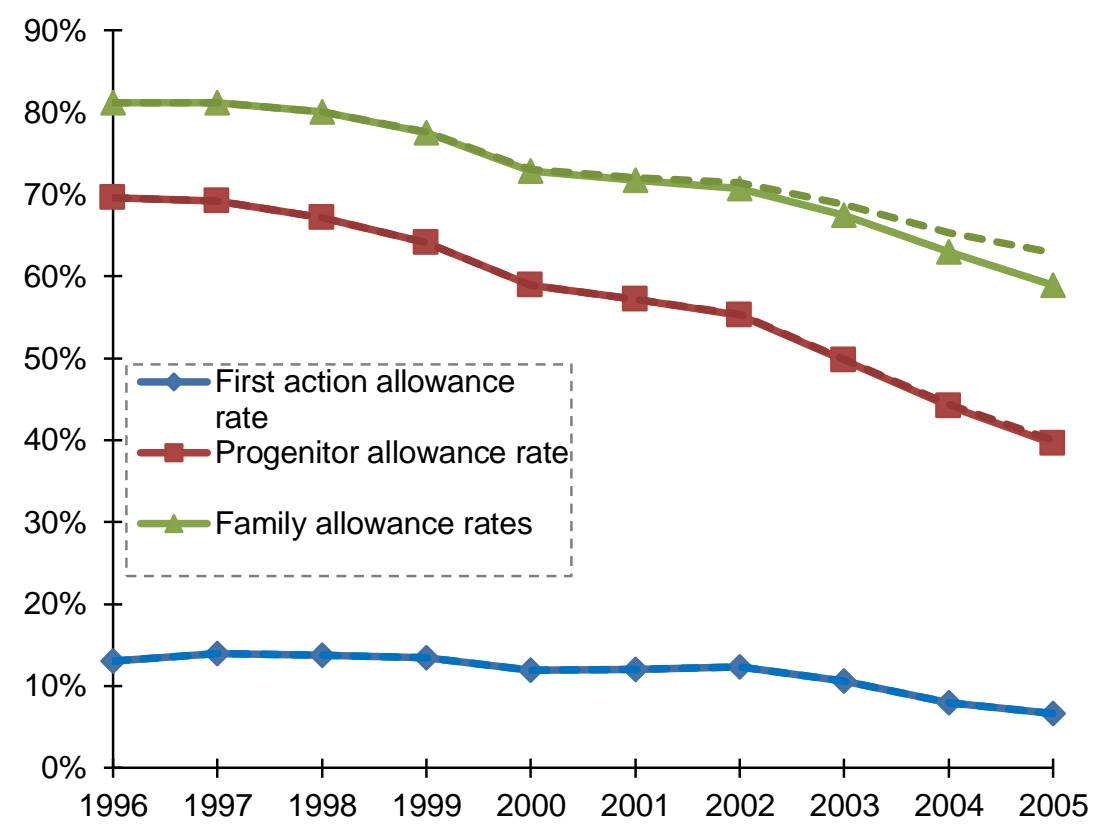

Figure 2 shows trends in the three types of allowance rates for applications filed at the USPTO for the first time between 1996 and 2005 and examined before June 30, 2013. Of the 2.15 million applications, 18,270 were pending as of June 30, 2013; the dotted lines (for the first-action allowance rate and the progenitor allowance rate) represent the corresponding rates if all pending applications are, in fact, allowed. These dotted lines represent the highest possible allowance rates. For progenitor applications that produced pending continuation applications, we assume that every pending continuation application will eventually be allowed. The dashed line represents the highest possible allowance rate.

Why did allowance rates decline between 1996 and 2005? Although proving causation is difficult, our interviews with patent experts at the USPTO suggested at least three plausible explanations for the decline. First, the financial market bust in March 2000 and the resulting financial constraints may have forced some inventors to abandon applications at a higher frequency than during "normal" times. Second, the USPTO introduced several procedures in 2000 that increased scrutiny of patent applications (for example, the "second pair of eyes" system, subjecting certain applications to mandatory assessment by more than one examiner before allowing them), which may have decreased the probability of patent allowance. Finally, the number of pending applications, as well as the lengths of first-action

observation shrinks, the observed allowance rates falls to $0 \%$ and the hypothetical maximum for each allowance rate approaches $100 \%$. 
and total pendency steadily increased during the period of our study. Longer pendency periods have been correlated with more abandonment, ${ }^{16}$ thus lowering the observed allowance rates. ${ }^{17}$ Of course, establishing causation or teasing out the relative contributions of the above three factors to changes in allowance rates is difficult, and future research should separate out the effects of changes in USPTO practices from changes in the frequency of abandonment.

\section{Allowance RAtes ACross Technology FieldS}

It is well known that patent value varies across industries. Inventors in discrete-product industries, such as the chemical and pharmaceutical industries, tend to use patents to preclude imitation by rivals, while those in complex product industries, such as the electronics and computers industries, amass patents to enhance bargaining power in cross-licensing negotiations. ${ }^{18}$ As a result, inventors in different industries appear to pursue different strategies during the patent examination process. Additionally, judicial decisions affect the standards of patentability for some technological fields, while leaving the standards unchanged for others. ${ }^{19}$

Figure 3 displays the patent allowance rates for the patenttechnology categories created by Bronwyn H. Hall, Adam B. Jaffe and Manuel Trajtenberg. ${ }^{20}$ Applications in Drugs and Medical Instruments have the lowest average allowance rate of $42.8 \%$, while applications in the Electrical and Electronics sectors enjoy the highest allowance rate of $66.6 \%$. Applicants appear to use continuation procedures more in sectors with lower allowance rates; for example, $44.1 \%$ of the progenitor applications in the Drugs and Medical sector used at least one of the continuation procedures. ${ }^{21}$ The decline in allowance rates is

16 See Benjamin Mitra-Kahn et al., UK Intellectual Prop. Office \& U.S. Patent \& Trademark Office, Patent Backlogs, Inventories, and Pendency: AN INTERNATIONAL FRAMEWORK 70-90 (2013), http://www.ipo.gov.uk/ipresearchuspatlog-201306.pdf.

17 Table A1 of the Supplementary Appendix presents the correlation between our allowance rate measures and the percent change in GDP from the previous year, the number of applications pending in the year of filing, and the total pendency for applications disposed in the year of filing. All three allowance rates are strongly negatively correlated with pendency and the number of pending applications. They are moderately positively correlated with the percent change in GDP.

18 See, e.g., Bronwyn H. Hall \& Rosemarie Ham Ziedonis, The Patent Paradox Revisited: An Empirical Study of Patenting in the US Semiconductor Industry, 1979-1995, 32 RAND J. ECON. 101, 107 (2001).

19 Ass'n for Molecular Pathology v. Myriad Genetics, Inc., 133 S.Ct. 1207 (2013); State Street Bank \& Trust Co. v. Signature Fin. Group, 149 F.3d 1368 (Fed. Cir. 1998).

20 See generally Hall et al., supra note 9. Hall, Jaffe, and Trajtenberg map U.S. Patent Classifications (USPC) to six technology categories for issued utility patent applications. Id. at $12-13,41-42$. We apply their mapping to all progenitor applications in our dataset to treat abandoned and issued applications similarly. Continuation applications are assigned to the same technology category as the progenitor application.

21 See Table A3 of the Supplementary Appendix. 
particularly striking for Drugs and Medical Instrument patents and Computers and Communication patents. In these sectors, both firstaction allowance rate and progenitor allowance rates declined by more than $50 \% .^{22}$

Figure 3: Allowance Rates by Technology Field (for Patent Applications Filed 1996-2005 and Examined Before Mid-2013)

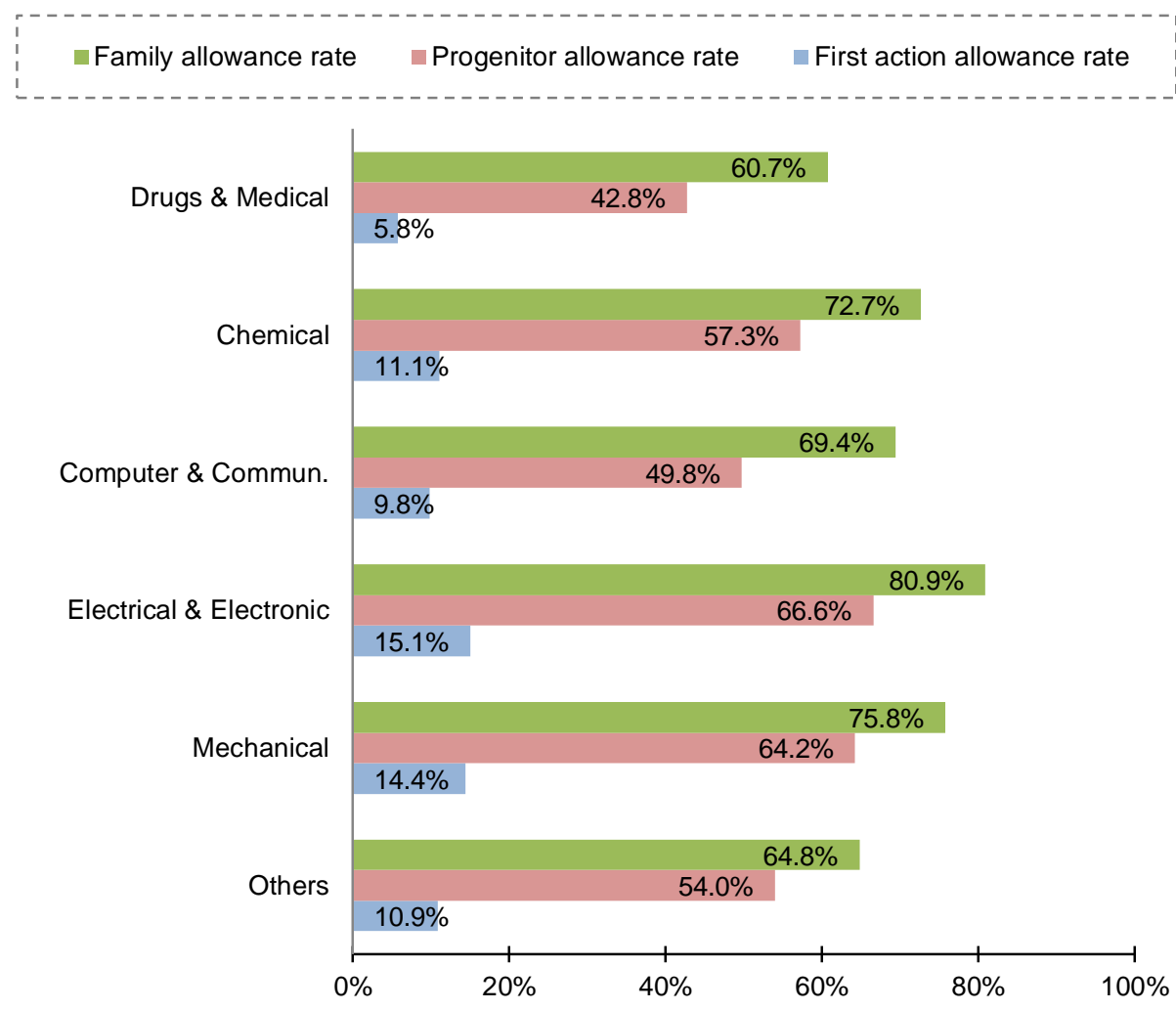

Figure 3 shows the three types of allowance rates across the six NBER patent-technology fields for applications filed at the USPTO for the first time between 1996 and 2005 and examined before mid2013.

\section{Allowance Rates ACross InVEntor TyPES}

Does the patent allowance rate differ for different applicant types, such as small or foreign inventors? To answer this, we identified applications as originating from foreign inventors if the primary inventor on the application was located abroad, and defined small inventors as those that qualified for the USPTO's small-entity discounts on application fees. Large foreign inventors accounted for $39 \%$ of the progenitor applications, large U.S. inventors for $31.1 \%$, small foreign inventors for $9.6 \%$, and small U.S. inventors for $20.1 \%$.

22 Figures A2-A4 of the Appendix compare sectorial trends for the three allowance rates. 
Figure 4 reveals that large foreign inventors enjoy the highest progenitor and family allowance rates (60.5\% and $77 \%$ respectively), followed by large U.S. inventors (57\% and $75.2 \%)$. Small U.S. inventors have the lowest allowance rates, particularly with respect to family allowance rate. Foreign applicants and small inventors are less likely to use continuation applications. ${ }^{23}$ The differences in allowance rates across applicant types appear more substantial in some fields (such as Computers and Communications) than others. ${ }^{24}$ The decline in first-action allowance rates and progenitor allowance rates appears pronounced for U.S. inventors, both large and small. ${ }^{25}$

\section{Figure 4: Allowance Rates by Inventor Type (for Patent Applications Filed from 1996-2005 and Examined Before Mid- 2013)}

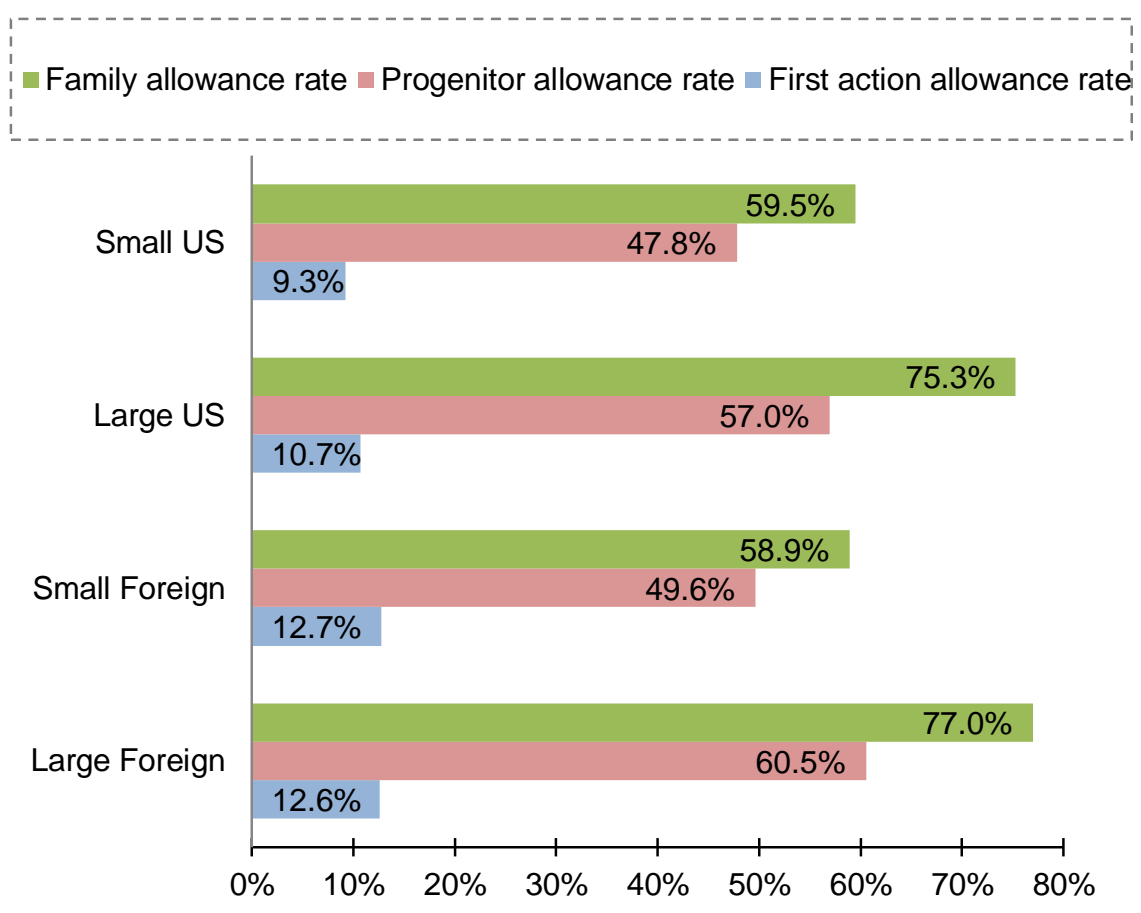

Figure 4 shows the three types of allowance rates across the four inventor types for applications filed at the USPTO for the first time between 1996 and 2005 and examined before mid-2013.

These numbers should be interpreted with caution. Lower allowance rates for small U.S. applicants could reflect higher propensity for abandonment or differences in the nature of subject

23 Table A4 of the Supplementary Appendix reports the percentage of progenitor applications that used the different types of continuations by applicant type.

24 Table A5 of the Supplementary Appendix reports the allowance rates for the different applicant types across technology fields.

25 Figures A5-A7 of the Supplementary Appendix present trends for the three types of allowance rates by applicant type. 
matter claimed in the applications. Similarly, large foreign inventors may enjoy higher allowance rates because they seek protection in the United States for only their most important inventions, or because they are more likely to have access to the necessary legal and financial resources.

\section{CONCLUSION}

Our analysis of U.S. patent applications filed between 1996 and 2005 and examined through mid-2013 counters the popular belief that the USPTO allows nearly all applications to emerge as patents. We find that the first-action allowance rate for patent applications is only $11.4 \%$, and the progenitor allowance rate is similarly low at $55.8 \%$. The family allowance rate, which accounts for continuations of progenitor applications, is $71.2 \%$. Furthermore, we find that the probability that a patent will issue has declined over time, dropping from $70 \%$ for the 1996 cohort to $40 \%$ for the 2005 cohort (even accounting for censoring issues as shown in Figure A1). Applications in the "Drugs and Medical Instruments" field are least likely to be successful, with allowance rates declining sharply during the period of our study, while applications in the "Electrical and Electronics" field are most likely to be successful. Regardless of technology category, however, allowance rates are lower for small inventors.

What are the policy implications of these findings? Many scholars have interpreted allowance rates, typically incorrectly calculated, to reflect examination quality alone and have argued that high allowance rates indicate low examination quality. ${ }^{26}$ Our findings challenge the popular belief that allowance rates are close to $100 \%$, and based on our calculated allowance rates, we find no evidence that the USPTO is becoming more lenient in granting patents. To the extent that some inventors invest in patent applications based on likelihood of success, our findings help correct misperceptions and enable more informed decisions about investments.

Our finding that patent applications filed by small inventors and those seeking to protect biomedical technologies were systematically less likely to emerge as patents, particularly in more recent years, is quite striking. Are small inventors' applications less likely to emerge as patents because they are more likely to file frivolous applications, or because they are more constrained in accessing the legal and financial resources required to prosecute their applications? Similarly, are patents in the biomedical fields less likely to issue because applications in these fields increasingly seek protection for less novel subject matter? Or are the changes driven by changes in the strategies of either patent applicants or examination-related policies at the USPTO? Answering these questions will help pinpoint the causes behind the substantial variation in patent allowance rates, and is the

26 See, e.g., Quillen \& Webster, Continuing Patent Applications, supra note 6; Quillen \& Webster, One More Time, supra note 6. 
next step towards developing policy responses to the variation. We leave this important investigation for future research.

Our study also suggests that policy makers should interpret patent allowance rates cautiously. Allowance rates are the product of an "opt out" system for applicants, driven not only by USPTO examination, but also by applicants' willingness to continue prosecution of their applications. Accordingly, allowance rates reflect the influence of several variables, including the patentability of the subject matter claimed, the rigor of the patent examination process, the length of application pendency, and the financial or legal costs of prosecution. As such, policymakers should recognize the difficulty of recommending changes to the examination system based on observed allowance rates. While a lenient patent examination process can impose costs on our innovation system, an overly rigorous examination process may deter inventors from seeking patents, or worse still, from investing in innovation. Achieving the right balance of encouragement and rigor will require further empirical analysis of the factors that influence fluctuations in allowance rates. 


\section{Appendix: Supplementary Statistics}

\section{Table A1: Correlations Between Allowance Rates and} Environmental Covariates, 1996-2005

\begin{tabular}{lccccc}
\hline & $(\mathrm{A})$ & $(\mathrm{B})$ & $(\mathrm{C})$ & (D) & (E) \\
\hline (A) First-Action Allowance Rate & & & & & \\
(B) Progenitor Allowance Rate & 0.949 & & & & \\
(C) Family Allowance Rate & 0.950 & 0.998 & & & \\
(D) Percent Change in Real GDP & 0.352 & 0.482 & 0.515 & & \\
(E) Total Pending Applications & -0.925 & -0.994 & -0.992 & -0.505 & \\
(F) Total Pendency & -0.925 & -0.967 & -0.963 & -0.349 & 0.971 \\
\hline
\end{tabular}

Table A1 shows contemporaneous correlations between allowance rates and potential environmental determinants of allowance rates. All variables are measured annually. "Total Pending Applications" refers to the stock of patent applications filed and undergoing the examination process for the given year. "Total Pendency" refers to the average time, in months, between patent application date and patent disposal date during the entry year of the progenitor applications.

Table A2: Progenitor Applications and Related Continuation Applications, 1996-2005

\begin{tabular}{cccccccc}
\hline Year & Applications & CON & CIP & DIV & Any & $\begin{array}{c}\text { Non- } \\
\text { Continuations } \\
\text { (RCEs) }\end{array}$ & $\begin{array}{c}\text { Either } \\
\text { Continuation }\end{array}$ \\
\hline 1996 & 146,260 & $6.9 \%$ & $5.6 \%$ & $6.5 \%$ & $17.7 \%$ & $11.2 \%$ & $24.9 \%$ \\
1997 & 166,232 & $5.8 \%$ & $5.3 \%$ & $6.7 \%$ & $16.5 \%$ & $12.1 \%$ & $25.6 \%$ \\
1998 & 182,717 & $6.3 \%$ & $5.0 \%$ & $6.8 \%$ & $16.9 \%$ & $13.4 \%$ & $26.9 \%$ \\
1999 & 197,704 & $6.9 \%$ & $5.0 \%$ & $6.9 \%$ & $17.5 \%$ & $14.5 \%$ & $28.3 \%$ \\
2000 & 222,480 & $7.1 \%$ & $4.8 \%$ & $6.5 \%$ & $17.2 \%$ & $15.7 \%$ & $29.0 \%$ \\
2001 & 232,668 & $7.1 \%$ & $4.4 \%$ & $6.5 \%$ & $16.9 \%$ & $17.4 \%$ & $30.3 \%$ \\
2002 & 233,246 & $6.7 \%$ & $4.4 \%$ & $6.1 \%$ & $16.1 \%$ & $19.7 \%$ & $31.5 \%$ \\
2003 & 235,861 & $6.3 \%$ & $4.1 \%$ & $5.1 \%$ & $14.6 \%$ & $24.1 \%$ & $33.7 \%$ \\
2004 & 250,338 & $6.3 \%$ & $3.4 \%$ & $4.9 \%$ & $13.7 \%$ & $27.3 \%$ & $35.6 \%$ \\
2005 & 278,160 & $6.5 \%$ & $2.7 \%$ & $4.7 \%$ & $13.2 \%$ & $29.2 \%$ & $37.1 \%$ \\
\hline
\end{tabular}

Table A2 shows the number of progenitor applications filed per year and the percentage of progenitor applications from each cohort that resulted in continuations. 
Table A3: The Use of Continuation Applications Across Technology Fields, 1996-2005

\begin{tabular}{lccccccc}
\hline $\begin{array}{l}\text { Technology } \\
\text { Field }\end{array}$ & Applications & CON & CIP & DIV & Any & $\begin{array}{c}\text { Non- } \\
\text { serialized } \\
\text { Contin- } \\
\text { uations } \\
\text { (RCEs) }\end{array}$ & $\begin{array}{c}\text { Either } \\
\text { Contin- } \\
\text { uation }\end{array}$ \\
\hline $\begin{array}{l}\text { Chemical } \\
\begin{array}{l}\text { Drugs \& } \\
\text { Medical }\end{array}\end{array}$ & 245,150 & $6.0 \%$ & $5.3 \%$ & $9.2 \%$ & $19.1 \%$ & $18.2 \%$ & $32.8 \%$ \\
$\begin{array}{l}\text { Computers } \\
\text { \& Comm. }\end{array}$ & 611,046 & $8.3 \%$ & $3.2 \%$ & $3.6 \%$ & $14.1 \%$ & $26.7 \%$ & $36.0 \%$ \\
$\begin{array}{l}\text { Electrical \& } \\
\text { Electronic }\end{array}$ & 402,401 & $4.7 \%$ & $3.0 \%$ & $7.7 \%$ & $14.5 \%$ & $16.4 \%$ & $27.5 \%$ \\
Mechanical & 311,040 & $3.9 \%$ & $3.8 \%$ & $4.9 \%$ & $11.9 \%$ & $13.2 \%$ & $22.7 \%$ \\
Others & 348,093 & $4.6 \%$ & $5.2 \%$ & $4.2 \%$ & $13.2 \%$ & $13.4 \%$ & $23.7 \%$ \\
\hline
\end{tabular}

Table A3 shows the number of progenitor applications filed in each NBER patenttechnology field and the percentage of progenitor applications that resulted in continuations.

Table A4: The Use of Continuation Applications Across Applicant Types, 1996-2005

\begin{tabular}{lccccccc}
\hline $\begin{array}{l}\text { Applicant } \\
\text { Type }\end{array}$ & Applications & CON & CIP & DIV & Any & $\begin{array}{c}\text { Non- } \\
\text { serialized } \\
\text { Contin- } \\
\text { uations } \\
\text { (RCEs) }\end{array}$ & $\begin{array}{c}\text { Either } \\
\text { Contin- } \\
\text { uation }\end{array}$ \\
\hline $\begin{array}{l}\text { Large } \\
\text { Foreign }\end{array}$ & 838,210 & $4.4 \%$ & $1.3 \%$ & $5.9 \%$ & $11.2 \%$ & $21.1 \%$ & $29.1 \%$ \\
Small & 207,460 & $3.7 \%$ & $3.7 \%$ & $2.9 \%$ & $9.7 \%$ & $12.1 \%$ & $19.3 \%$ \\
Foreign & 668,527 & $9.2 \%$ & $5.2 \%$ & $7.6 \%$ & $20.4 \%$ & $23.0 \%$ & $37.6 \%$ \\
Large US & 431,469 & $8.2 \%$ & $9.2 \%$ & $5.0 \%$ & $20.5 \%$ & $14.3 \%$ & $30.0 \%$ \\
Small US & & & & & & &
\end{tabular}

Table A4 shows the number of progenitor applications filed by applicant type and the percentage of progenitor applications that resulted in continuations. 
Table A5: Allowance Rates Across Applicant Types and Technology Fields, 1996-2005

\begin{tabular}{|c|c|c|c|c|c|}
\hline $\begin{array}{l}\text { Technology } \\
\text { Field }\end{array}$ & $\begin{array}{l}\text { Applicant } \\
\text { Type }\end{array}$ & Applications & First Action & Progenitor & Family \\
\hline \multirow{4}{*}{ Chemical } & Large Foreign & 112,598 & $11.0 \%$ & $59.6 \%$ & $75.4 \%$ \\
\hline & Large U.S. & 76,595 & $11.3 \%$ & $57.2 \%$ & $74.1 \%$ \\
\hline & Small Foreign & 20,245 & $11.6 \%$ & $52.9 \%$ & $64.4 \%$ \\
\hline & Small U.S. & 35,712 & $9.7 \%$ & $52.4 \%$ & $65.8 \%$ \\
\hline \multirow{4}{*}{$\begin{array}{l}\text { Computers \& } \\
\text { Comm. }\end{array}$} & Large Foreign & 244,453 & $11.7 \%$ & $54.5 \%$ & $74.0 \%$ \\
\hline & Large U.S. & 251,253 & $8.9 \%$ & $51.8 \%$ & $74.1 \%$ \\
\hline & Small Foreign & 32,847 & $9.6 \%$ & $37.7 \%$ & $48.9 \%$ \\
\hline & Small U.S. & 82,493 & $6.4 \%$ & $34.5 \%$ & $49.6 \%$ \\
\hline \multirow{4}{*}{$\begin{array}{l}\text { Drugs \& } \\
\text { Medical }\end{array}$} & Large Foreign & 62,142 & $5.3 \%$ & $45.0 \%$ & $63.6 \%$ \\
\hline & Large U.S. & 69,632 & $6.0 \%$ & $43.1 \%$ & $62.7 \%$ \\
\hline & Small Foreign & 27,372 & $5.7 \%$ & $39.9 \%$ & $55.4 \%$ \\
\hline & Small U.S. & 68,790 & $5.6 \%$ & $41.5 \%$ & $58.3 \%$ \\
\hline \multirow{4}{*}{$\begin{array}{l}\text { Electrical \& } \\
\text { Electronics }\end{array}$} & Large Foreign & 204,125 & $15.5 \%$ & $67.7 \%$ & $83.3 \%$ \\
\hline & Large U.S. & 122,529 & $14.2 \%$ & $69.3 \%$ & $84.5 \%$ \\
\hline & Small Foreign & 30,489 & $17.0 \%$ & $57.7 \%$ & $65.2 \%$ \\
\hline & Small U.S. & 45,258 & $13.1 \%$ & $60.0 \%$ & $71.1 \%$ \\
\hline \multirow{4}{*}{ Mechanical } & Large Foreign & 128,328 & $15.1 \%$ & $68.8 \%$ & $82.1 \%$ \\
\hline & Large U.S. & 74,681 & $14.1 \%$ & $67.2 \%$ & $80.5 \%$ \\
\hline & Small Foreign & 40,274 & $15.8 \%$ & $56.2 \%$ & $63.7 \%$ \\
\hline & Small U.S. & 67,757 & $12.0 \%$ & $57.1 \%$ & $65.9 \%$ \\
\hline \multirow{4}{*}{ Others } & Large Foreign & 86,564 & $11.3 \%$ & $60.7 \%$ & $74.6 \%$ \\
\hline & Large U.S. & 73,837 & $9.9 \%$ & $56.5 \%$ & $71.9 \%$ \\
\hline & Small Foreign & 56,233 & $13.5 \%$ & $51.1 \%$ & $57.7 \%$ \\
\hline & Small U.S. & 131,459 & $9.5 \%$ & $49.3 \%$ & $57.4 \%$ \\
\hline
\end{tabular}

Table A5 shows the number of progenitor applications filed in each of the six NBER patent-technology fields by applicant type and the percentage of each type's applications that produced the different types of continuations. 


\section{Figure A1: Trends in Allowance Rates with Adjustments for} Censoring, for Applications Filed Between 1991-2010

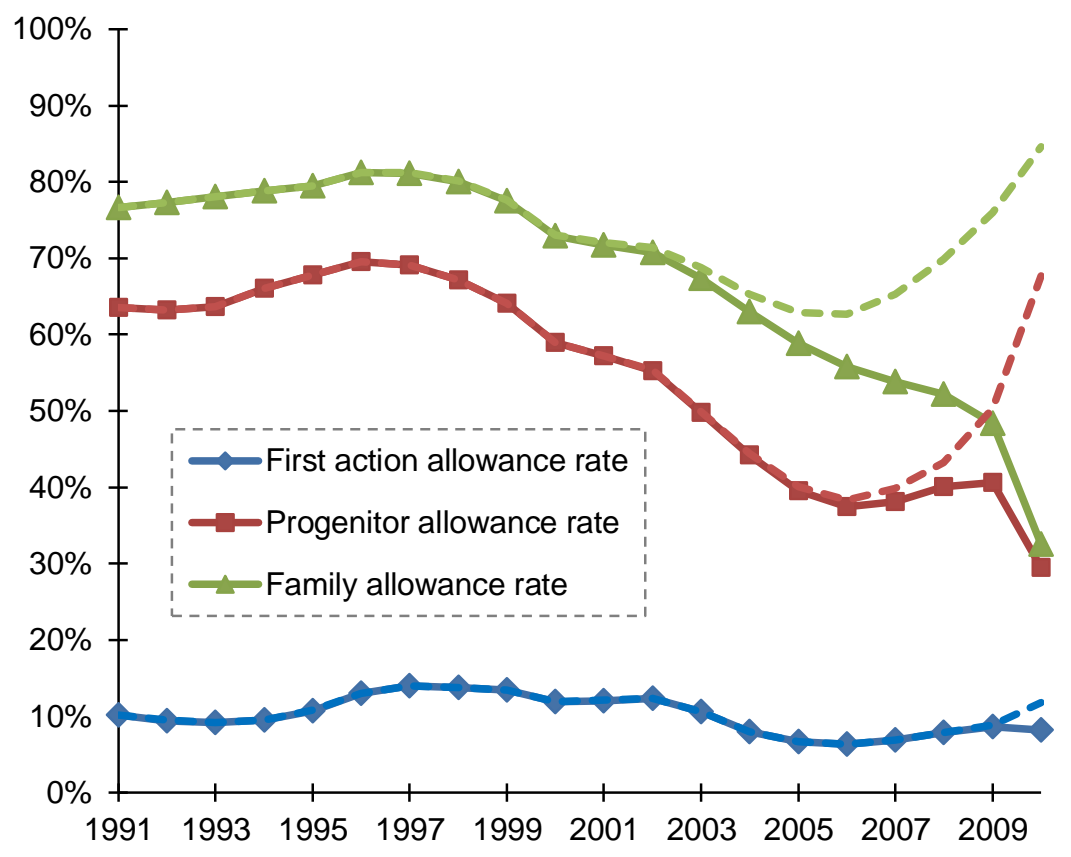

Figure A1 shows trends in the three types of allowance rates for the 4.2 million applications filed at the USPTO for the first time between 1991-2010. A significant number of applications filed after 2005 were pending as of June 30, 2013; the dotted lines (for the first-action allowance rate and the progenitor allowance rate) represent the corresponding rates if all pending applications are, in fact, allowed. These dotted lines represent the highest possible allowance rates. For progenitor applications that produced pending continuation applications, we assume that every pending continuation application will eventually be allowed. The dashed line therefore represents the highest possible family allowance rate. 
Figure A2: Trends in First-Action Allowance Rate by Technology Field

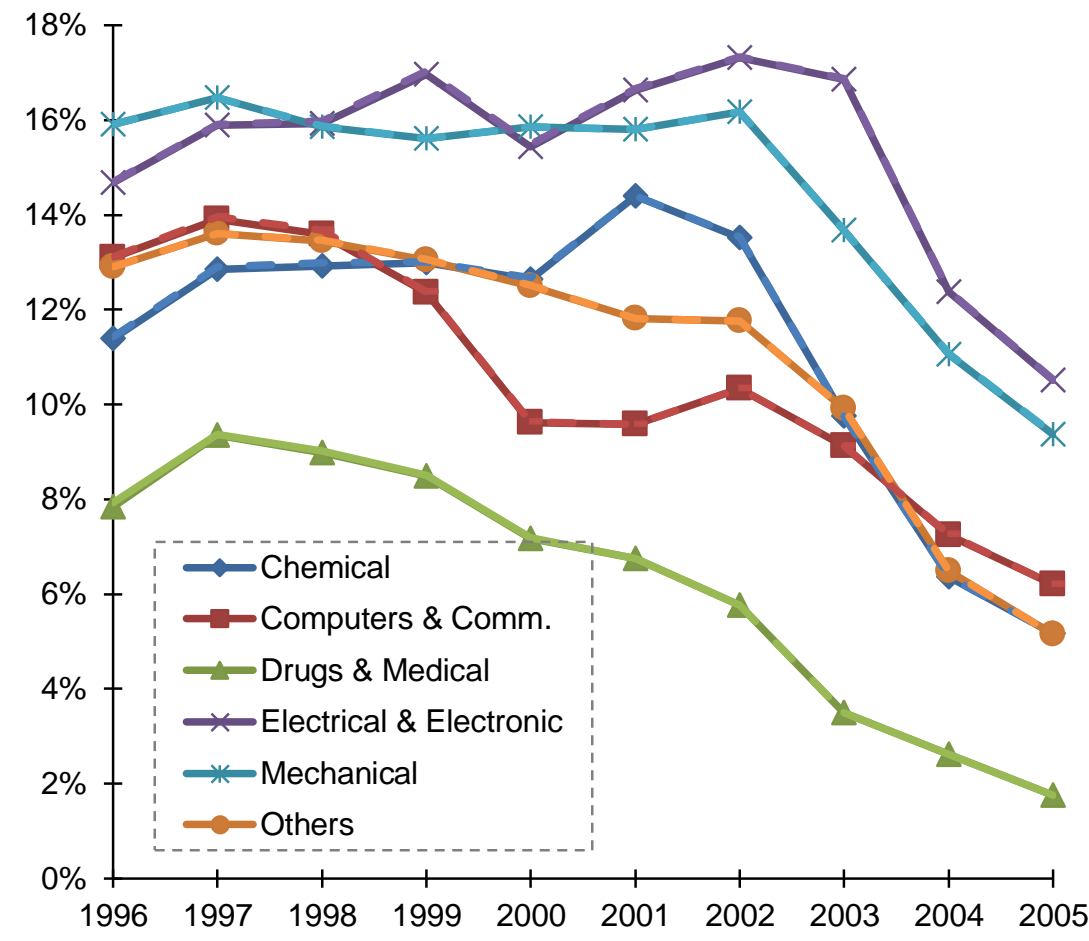

Figure A3: Trends in Progenitor Allowance Rate by Technology Field

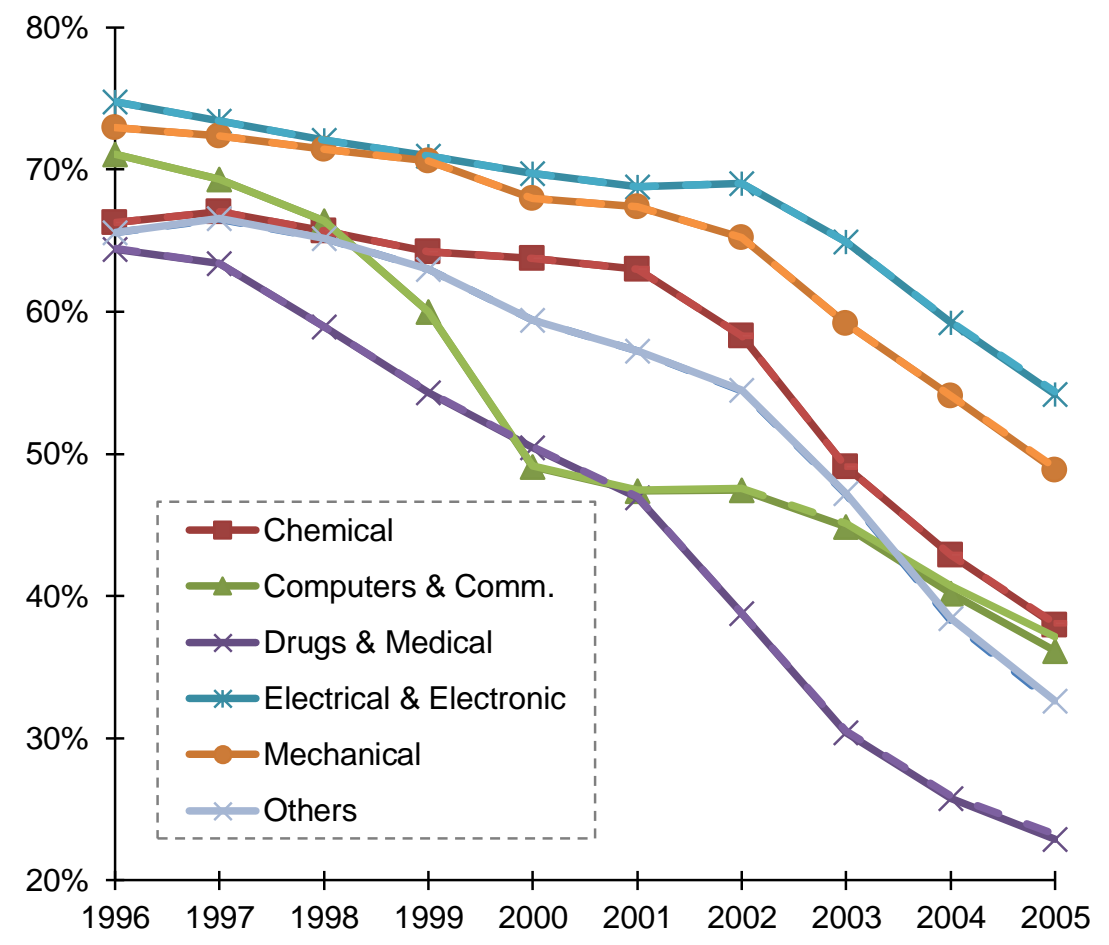


Figure A4: Trends in Family Allowance Rate by Technology Field

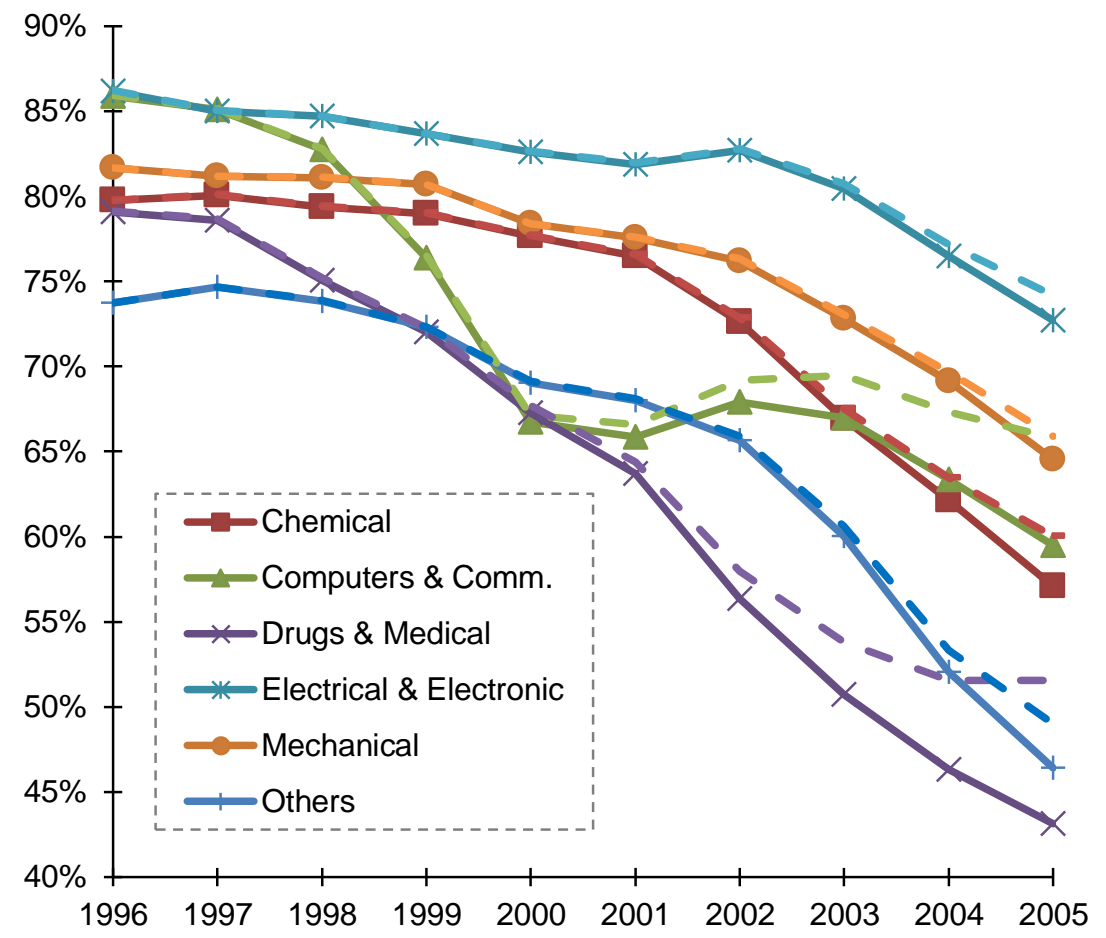

Figure A5: Trends in First-Action Allowance Rate by Applicant Type

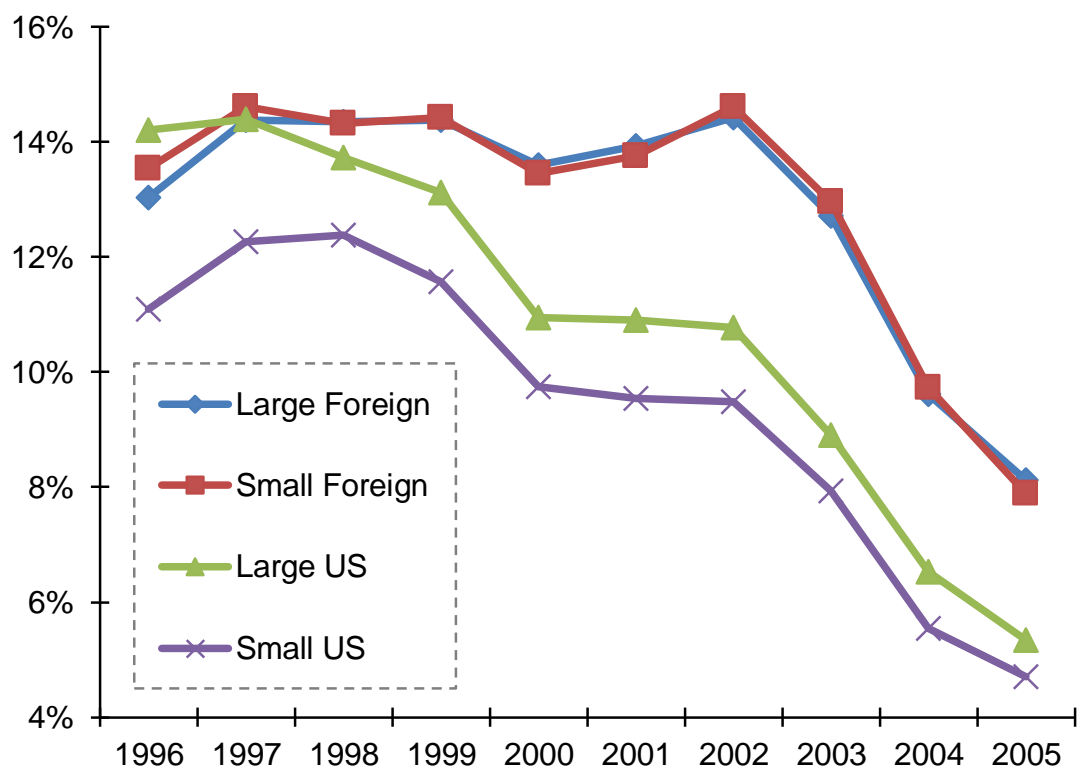


Figure A6: Trends in Progenitor Allowance Rate by Applicant Type

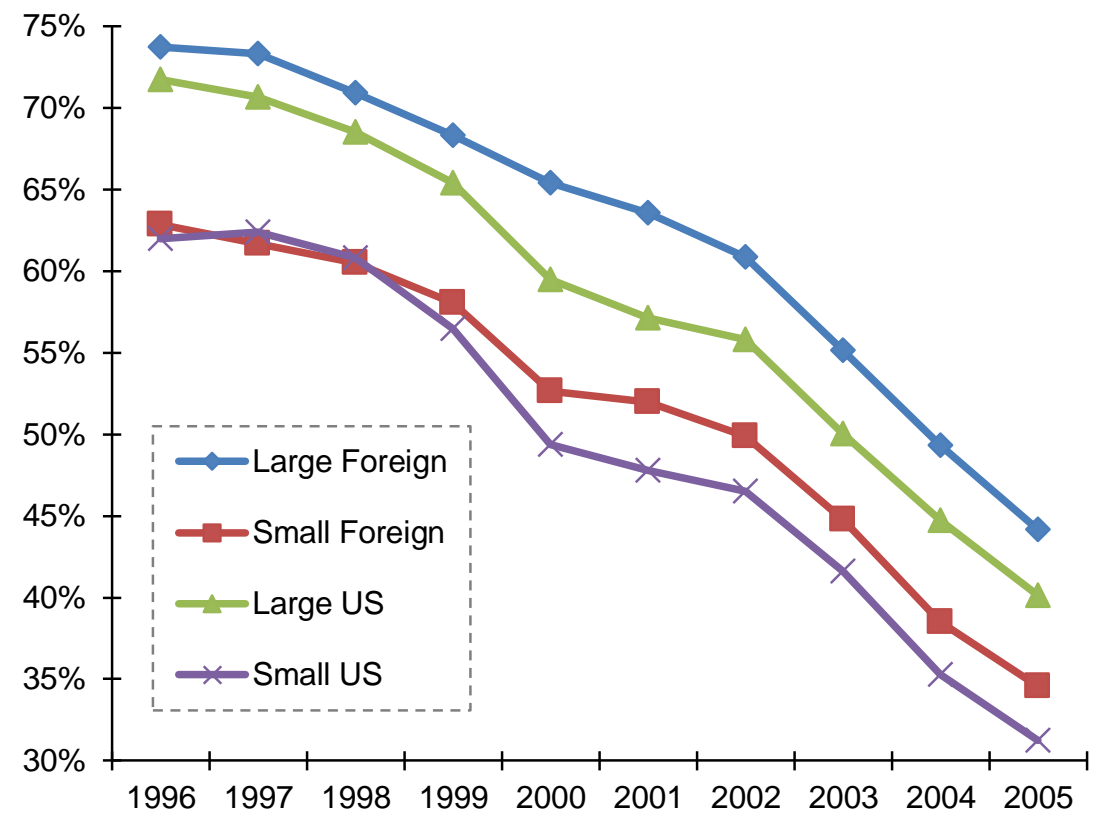

Figure A7: Trends in Family Allowance Rate by Applicant Type, 1996-2005

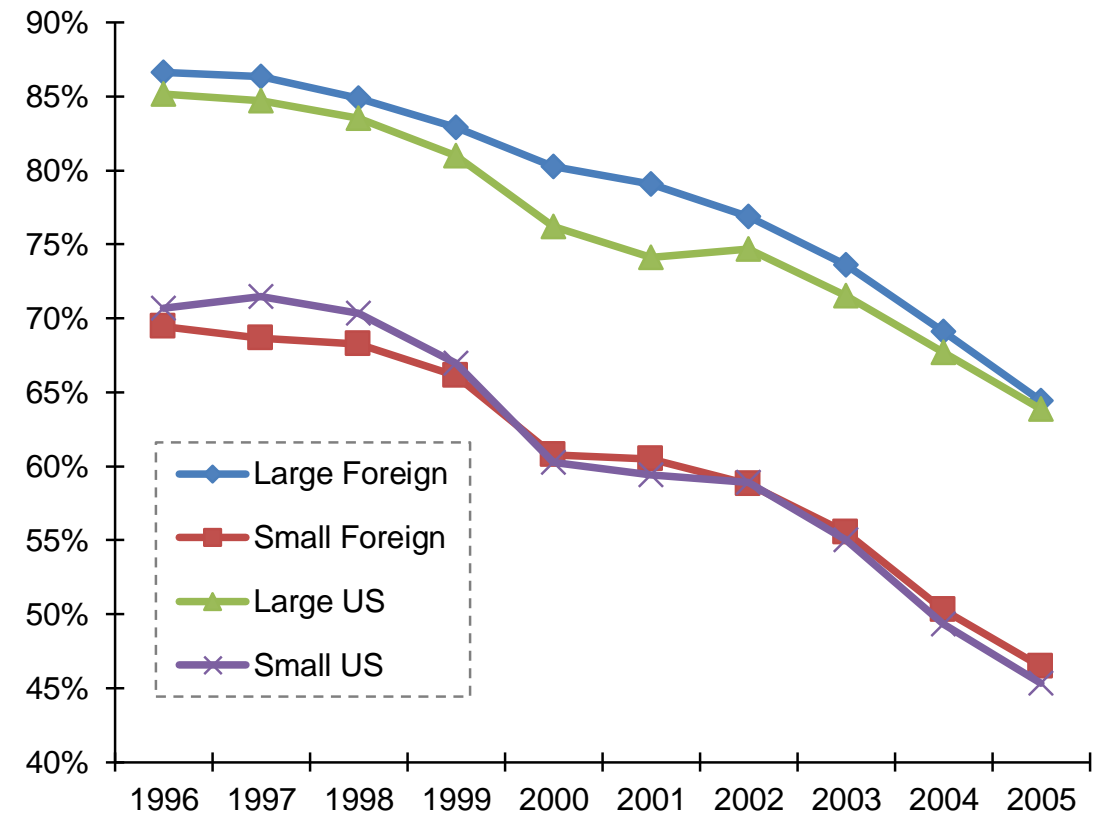

